\title{
The role of ultrasonography in detecting urinary tract calculi compared to CT scan
}

This article was published in the following Dove Press journal: Research and Reports in Urology

Fisal Ahmed,' MohammadReza Askarpour,' Ali Eslahi,' Hossein-Ali Nikbakht, ${ }^{2}$ Seyed-Hamed Jafari, ${ }^{3}$ Abbas Hassanpour,' Alireza Makarem, ${ }^{1}$ Hussein Salama, ${ }^{2}$ Abbas Ayoub ${ }^{3}$

'Department of Urology, Shiraz University of Medical Sciences, Shiraz, Iran; ${ }^{2}$ Student Research Committee, Shiraz Medical University, Shiraz, Iran; ${ }^{3}$ Department of Radiology, Shiraz University of Medical Sciences, Shiraz, Iran

\section{Video abstract}

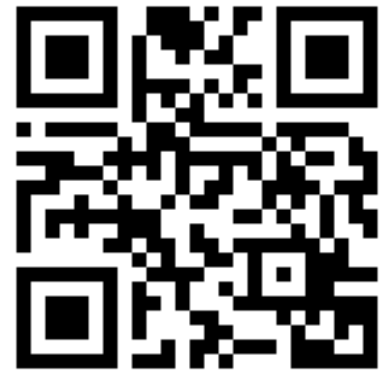

Point your SmartPhone at the code above. If you have a QR code reader the video abstract will appear. Or use: http://youtu.be/8eGVIKjf48c

Correspondence: Fisal Ahmed Department of Urology, Zand Street, Faghihi Hospital, Shiraz University of Medical Sciences, Shiraz 7135744619, Iran Tel +98 7I32326645

Fax +98 7132326645

Email fmaaa2006@yahoo.com
Objective: To evaluate the accuracy of ultrasonography (US) in measuring the urinary tract stone using non-contrast computed tomography (NCCT) as the standard reference.

Patients and methods: A total of 184 patients suspected with urolithiasis who had undergone NCCT and US radiologic investigation from 2015 to 2017 were enrolled in this study. The sensitivity, specificity, and stone size measured in US were validated by NCCT. Data of the stone size in US were classified into four groups $(0-3.5,3.6-5,5.1-10,>10 \mathrm{~mm})$ and then compared with NCCT data. Results: In 184 patients, NCCT detected 276 (97.2\%) stones, while US could identify 213 (75.5\%) stones. Overall sensitivity and specificity of US were $75.4 \%$ and $16.7 \%$, respectively. Detection rate of mid and distal ureteral stone was lower than that at other locations. The detection rate increased with the stone size. About $73 \%$ concordance was obtained for the stone size measured by US and NCCT (Pearson's correlation coefficient was 0.841). Factors such as the stone size, amount of hydronephrosis, and weight affected the detection rate of the urinary tract stone using US ( $P<0.001, P=0.02$, and $P=0.01$, respectively).

Conclusion: The stone size obtained by US was almost the same as that detected by NCCT; however, US is a limited imaging modality in detecting urinary tract stone, especially when used by an inexperienced radiologist, and in the case of smaller stone size, increased weight, and low grade of hydronephrosis.

Keywords: non-contrast computed tomography, ultrasonography, urinary tract, stone

\section{Plain language summary}

This study was designed to evaluate the accuracy of ultrasonography (US) detection of stones compared to computed tomographic scan as a standard method. A total of 184 patients suspected with urolithiasis who underwent non-contrast enhanced computed tomography (NCCT) and US radiologic investigation were enrolled in this study. The sensitivity, specificity, and stone size measured by US were determined by NCCT. Data of the stone size in US were classified into four groups $(0-3.5,3.6-5,5.1-10,>10 \mathrm{~mm})$ and then compared with NCCT data.

Overall sensitivity and specificity of US were $75.4 \%$ and $16.7 \%$, respectively. About $73 \%$ concordance was obtained for the stone size measured by US and NCCT (Pearson's correlation coefficient was 0.841 ). Factors such as the stone size, the amount of hydronephrosis) and weight affected the detection rate of the urinary tract stone, especially when used by an inexperienced radiologist.

\section{Introduction}

Urolithiasis is one of the most prevalent and current diseases among urologic disorders with a lifetime incidence of $12 \% .^{1}$ The gold standard imaging modality to diagnose 
urinary tract stone in patients with acute flank pain is noncontrast enhanced computed tomography (NCCT), which was reported to have a specificity of $94 \%-99 \%$ and sensitivity of $95 \%-98 \%{ }^{2}$ High ionizing dose, high rate of incidental findings, and high cost of NCCT are the limiting factors to its widespread use. ${ }^{2}$ On the other hand, ultrasonography (US) is widely used for detecting renal stone; it is a safe, noninvasive, and cheap method and in circumstances such as pregnancy and pediatric age, it is the modality of choice for calculi detection. ${ }^{3}$ Previous studies report the sensitivity and specificity of US for detecting renal stones as $24 \%-81 \%$ and $83 \%-100 \%$, respectively. ${ }^{4,5}$

However, many factors such as body mass index, age, and stone size affect the diagnosis of ureteric stone using US. ${ }^{6}$ The aim of this study was to determine the efficacy of US for detecting urinary tract stones by using computed tomography as the gold standard reference.

\section{Patients and methods}

This study was conducted from 2015 to 2017 on 184 patients who visited the emergency department, of whom 121 (65.5\%) were men and $63(34.5 \%)$ were women. Indications for radiologic investigation were acute flank pain in $120(65.2 \%)$ cases, hematuria in $13(7.1 \%)$ cases, and a history of previous urinary tract stones in $51(27.7 \%)$ subjects.

All patients with staghorn stone and urinary tract diversions, those who received NCCT in other hospitals, patients with a time interval of $>1$ month between US and NCCT, those with a probability of stone displacement, and pregnant women were excluded from this study. All clinical data including age, weight, sex, stone location and size, and skin to stone distance in NCCT were collected. NCCT was performed from the upper abdominal area to the pelvis with the image reconstructed at 1 or $2 \mathrm{~mm}$ interval. US was performed by a senior radiologist with 3 years of experience using gray-scale US (Ws850; Samsung, Seoul, South Korea) with a 3-5 MHz curved transducer. Since a small stone may not cause an acoustic shadow, all echogenic foci seen in the renal pelvis, ureter, or calices on US were diagnosed as urinary tract stones. The sensitivity, specificity, and accuracy of US for detecting the urinary tract stone were recorded. Furthermore, the stones were classified according to their size into groups $0-3.5,3.6-5,5.1-10$, and $>10 \mathrm{~mm}$ using NCCT as the gold standard.

\section{Statistical analysis}

Data are presented as means and SDs, or frequency and percentage, where appropriate. Independent $t$-test was used to analyze the differences in continuous variables, and for comparison of qualitative data, chi-squared or Fisher's exact test was used. Pearson's correlation was calculated to determine the correlation between the size in NCCT and US. Additionally, Bland-Altman plots and Pitman's tests were applied to compare the urinary tract stone sizes in the NCCT and US assessment methods. Data were entered into SPSS Version 21 and STATA Version 12. $P$-values of $<0.05$ were considered significant.

\section{Results}

In this study, 284 stones were detected in 184 patients. The mean age of the patients was $47.7 \pm 15.9$ years. The mean right- and left-side stone detection was 52.8\% (149) and $47.2 \%$ (133), respectively. The mean weight of the patients was $72.7 \pm 11.3 \mathrm{~kg}$. The mean stone size in NCCT was $8.9 \pm 4.9$ $\mathrm{mm}$.

NCCT could identify $276(97.2 \%)$ stones, while US could detect $213(75.5 \%)$ stones. The sensitivity of US with CI was $75.4 \%(0.7-0.8)$, and the specificity of US with CI was $16.7 \%$ (0.03-0.56); also, the positive predictive value and the negative predictive value were $97.18 \%$ and $1.69 \%$, respectively.

The detection rate of specific stone by US was examined for different locations (Table 1); it was found that the detection sensitivity rate was low in the mid and distal parts of the right ureter and in the left distal ureter $(42.8 \%, 39.2 \%$, and $43.4 \%$, respectively).

We also examined the detection rate of US according to the size of the stone (Table 2), and the detection rate was found to increase with size. The sensitivity levels for $0-3.5$, $3.6-5,5.1-10$, and $>10 \mathrm{~mm}$ were $55.8 \%, 73.9 \%, 71.7 \%$, and $89.4 \%$, respectively, and it was considered clinically important when the stone size was $>5 \mathrm{~mm}$.

To obtain the accuracy of the stone size measured by US, we compared the stone size of both NCCT and US. About $73 \%$ concordance was obtained for the stone size measured by US and NCCT (Pearson's correlation coefficient was $0.841 ; P<0.001)$. Then, we classified the stone sizes into four groups $(0-3.5,3.6-5,5.1-10$, and $>10 \mathrm{~mm})$ and measured the sizes separately by US and NCCT.

The Bland-Altman plots from US and NCCT limits of agreement for the stone size were between -5.659 and 5.745 and the mean difference $(95 \% \mathrm{CI})$ was $0.043(0.346-0.432)$. The spread around the mean for the stone size showed variations across all levels and only a few participants fell outside the limit of agreement. The mean difference was not associated with the means of the two methods, confirming the acceptable level of agreement (Figure 1). 
Table I Detection rate of the urinary tract stone by ultrasonography based on location

\begin{tabular}{|c|c|c|c|c|c|c|c|c|}
\hline \multirow[t]{2}{*}{ Location } & \multirow{2}{*}{$\begin{array}{l}\text { Left } \\
\text { Total } \\
\text { no. }\end{array}$} & \multirow{2}{*}{$\begin{array}{l}\text { Kidney } \\
\text { Detected } \\
\text { no. }\end{array}$} & \multirow{2}{*}{$\begin{array}{l}\text { Missed } \\
\text { no. }\end{array}$} & \multirow{2}{*}{$\begin{array}{l}\text { Sensitivity } \\
\text { (\%) }\end{array}$} & \multirow{2}{*}{$\begin{array}{l}\text { Right } \\
\text { Total } \\
\text { no. }\end{array}$} & \multirow{2}{*}{$\begin{array}{l}\text { Kidney } \\
\text { Detected } \\
\text { no. }\end{array}$} & \multirow{2}{*}{$\begin{array}{l}\text { Missed } \\
\text { no. }\end{array}$} & \multirow{2}{*}{$\begin{array}{l}\text { Sensitivity } \\
\text { (\%) }\end{array}$} \\
\hline & & & & & & & & \\
\hline Upper pole & 12 & 9 & 3 & 75.0 & 14 & 11 & 3 & 78.5 \\
\hline Mid pole & 16 & 13 & 3 & 81.2 & 25 & 20 & 5 & 80.0 \\
\hline Lower pole & 47 & 42 & 5 & 89.3 & 42 & 37 & 5 & 88.0 \\
\hline Renal pelvis & 16 & 14 & 2 & 87.5 & 21 & 20 & 1 & 95.2 \\
\hline Proximal ureter & 19 & 13 & 6 & 68.4 & 12 & 10 & 2 & 83.3 \\
\hline Mid ureter & 0 & 0 & 0 & 0 & 7 & 3 & 4 & 42.8 \\
\hline Distal ureter & 23 & 10 & 13 & 43.4 & 28 & 11 & 17 & 39.2 \\
\hline
\end{tabular}

Table 2 Stone size in NCCT

\begin{tabular}{|l|l|l|l|l|}
\hline $\begin{array}{l}\text { Stone size in } \\
\text { NCCT }(\mathbf{m m})\end{array}$ & $\begin{array}{l}\text { Total } \\
\text { no. }\end{array}$ & $\begin{array}{l}\text { Detected } \\
\text { by US }\end{array}$ & $\begin{array}{l}\text { Missed } \\
\text { by US }\end{array}$ & $\begin{array}{l}\text { Sensitivity } \\
\text { (\%) }\end{array}$ \\
\hline $0-3.5$ & 34 & 19 & 15 & $55.8^{\mathrm{a}}$ \\
$3.6-5$ & 46 & 34 & 12 & $73.9^{\mathrm{b}}$ \\
$5.1-10$ & 117 & 84 & 33 & $71.7^{\mathrm{c}}$ \\
$>10$ & 85 & 76 & 9 & 89.4 \\
\hline
\end{tabular}

Notes: ${ }^{a} P(0-3.5$ vs $3.5-5)=0.09, P(0-3.5$ vs $>10)=<0.001$. b $P(3.6-5$ vs $>10)=0.021$. cP $(5 . I-10$ vs $>10)=0.002$.

Abbreviations: NCCT, non-contrast enhanced computed tomography; US, ultrasonography.

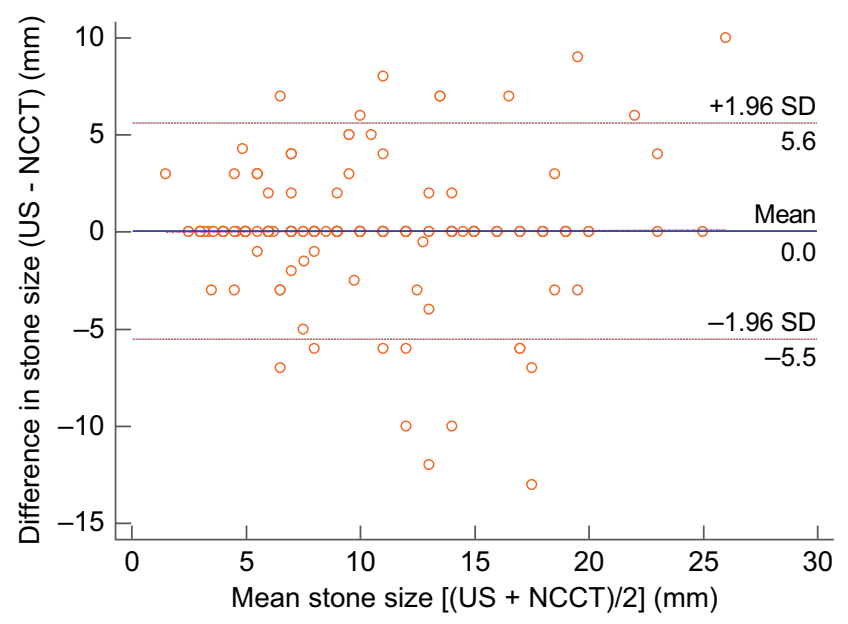

Figure I The Bland-Altman plots from US and NCCT limits of agreement for the stone size were between -5.659 and 5.745 and the mean difference $(95 \% \mathrm{Cl})$ was $0.043(0.346-0.432)$.

Notes: The spread around the mean for the stone size showed variations across all levels, and only a few participants fell outside the limit of agreement. The mean difference was not associated with the means of the two methods, confirming the acceptable level of agreement.

Abbreviations: NCCT, non-contrast enhanced computed tomography; US, ultrasonography.

The size of the stones that were missed by US was significantly smaller than that of the stones detected by NCCT. Many factors affect the detection of renal stone by US (Table 3). The stone size, amount of hydronephrosis (HDN), and weight affected the detection rate of the urinary tract stone using US ( $P<0.001, P=0.02$, and $P=0.01$, respectively).
Table 3 Factors affecting the US detection rate

\begin{tabular}{|c|c|c|c|}
\hline Factors & $\begin{array}{l}\text { US, } \\
\text { positive } \\
(n=2 \mid 3)\end{array}$ & $\begin{array}{l}\text { US, } \\
\text { negative } \\
(n=69)\end{array}$ & $P$-value \\
\hline Mean age (years) $\pm S D$ & $47.8 \pm 15.6$ & $47.1 \pm 17.4$ & 0.74 \\
\hline Mean weight $(\mathrm{kg}) \pm \mathrm{SD}$ & $71.7 \pm 11.0$ & $77.0 \pm 12.0$ & 0.01 \\
\hline Mean stone size $(\mathrm{mm}) \pm \mathrm{SD}$ & $9.7 \pm 5.2$ & $6.72 \pm 3.1$ & $<0.001$ \\
\hline \multicolumn{4}{|l|}{ Mean SSD $(\mathrm{mm}) \pm \mathrm{SD}$} \\
\hline Posterior & $87.6 \pm 26.4$ & $95.4 \pm 27.5$ & 0.11 \\
\hline Lateral & $95.7 \pm 24.8$ & $98.3 \pm 33.6$ & 0.66 \\
\hline Anterior & $101.8 \pm 19.2$ & $109.2 \pm 26.0$ & 0.26 \\
\hline $\begin{array}{l}\text { Mean stone density } \\
(\mathrm{HU}) \pm \mathrm{SD}\end{array}$ & $542.3 \pm 24.8$ & $482.3 \pm 272.9$ & 0.13 \\
\hline \multicolumn{4}{|l|}{ Amount of hydronephrosis } \\
\hline Normal & 75 & 14 & 0.02 \\
\hline Mild & 87 & 32 & \\
\hline Moderate & 43 & 15 & \\
\hline Severe & 8 & 8 & \\
\hline \multicolumn{4}{|l|}{ Stone in KUB X-ray } \\
\hline Opaque & 29 & 5 & 0.11 \\
\hline Radiolucent & 184 & 64 & \\
\hline \multicolumn{4}{|l|}{ Laterality } \\
\hline Left & 100 & 33 & 0.60 \\
\hline Right & 113 & 36 & \\
\hline \multicolumn{4}{|l|}{ Sex } \\
\hline Male & 93 & 28 & 0.10 \\
\hline Female & 54 & 9 & \\
\hline
\end{tabular}

Note: $P$-values of $<0.05$ were considered significant.

Abbreviations: KUB, kidney, ureters, bladder; SSD, skin to stone distance; US, ultrasonography; SD, standard deviation.

\section{Discussion}

The gold standard modality used for detecting renal stone is NCCT, whereas US is popularly used as the first investigation and it can make important decisions concerning the renal stone diagnosis. ${ }^{7}$ A recent study suggests that US is of limited value in the diagnosis of urinary stone, particularly renal stone. ${ }^{3}$ In the current study, in line with the literature reports, sonography was less sensitive than NCCT in initially detecting stones when located in the mid or distal part of the ureter and this may be due to obscurity by the bowel gas. ${ }^{8}$

Fowler et al, in a retrospective study, detected renal stones with a sensitivity of $24 \%$ and specificity of $90 \%$ within an 
interval of 30 days, and US detected only 24 out of 101 stones detected by NCCT. ${ }^{9}$ Patlas et al compared US and NCCT for detection of ureteric stone in 62 patients, yielding a sensitivity of $93 \%$ and specificity of $95 \%{ }^{8}$

Despite all these differences, in our study, the sensitivity of US for detection of stones was similar to that previously reported (about 75.4\%), whereas the specificity was not nearly as good as those given in the previous reports.

The factors behind low specificity of this study seems to be using inexperienced radiologist as our radiologist staff, suggesting that handling experience might have contributed to the improved detection of US, and the interval between NCCT and US was 30 days.

Other factors that may affect US diagnosis include the presence of HDN, stones abutting renal sinus fat, and vascular calcifications, as well as experience and knowledge of the upper urinary tract anatomy and the presence of bowel gas, which may obscure the ureteral calculi. Additionally, measurement of stones in multiple orthogonal planes affects reproducibility. Vascular calcifications and other artifacts may also be mistaken for stones and may partially account for the reduction in specificity. ${ }^{10-12}$

In another study, Kanno et al showed that the stone sizes detected by US were almost the same as those detected by NCCT. ${ }^{7}$ Similarly, in our study, about $73 \%$ concordance obtained for the stone size confirms the reliability of the stone size measurement by US and suggests that US might be adequate and worth performing.

A previous study investigated the factors affecting the accuracy of US for the detection of urinary stone. Goertz reported that the increasing degree of HDN was associated with an increase in the ureteric stone diagnosis using US. ${ }^{13}$ Kanno et al reported that the stone size in US was associated with detection rate of the renal stone. ${ }^{7}$ Our result was close to the previous study and found that the stone size and increasing degree of HDN are associated with increasing detection rate of urinary stone in US.

Pichler et al reported that age and body mass index affected the diagnosis of ureteral stone by US. ${ }^{6}$ In contrast, our study suggests that the detection rate of the urinary tract stone is not correlated with age; however, it is correlated with weight.

Ray et al demonstrated that increased skin to stone distance was significantly associated with US and NCCT discordance, which was not similar to our findings. ${ }^{14}$ We also determined that the stone density and opacity did not affect the detection rate of the urinary tract stone.
Some of the limitations of this study were the small sample size and the use of US which is an observer-dependent technique.

\section{Conclusion}

The stone size obtained by sonography was almost the same as that detected by NCCT; however, it is a limited imaging modality in detecting urinary tract stone, especially when used by an inexperienced radiologist, and in the case of smaller stone size, increased weight, and low grade of HDN. However, US still plays an important role in the primary diagnosis of patients with suspected urinary tract stone, as well as during the follow-up.

\section{Ethics statement}

We declare that our study was approved by the ethical committee of Shiraz University of Medical Sciences with code number: 15408-01-01-1396. All permissions were acquired through the authorities legally, and since this study was a retrospective study and the name and data of individuals were kept hidden in reports, patient consent was not required.

\section{Acknowledgments}

The authors would like to thank Shiraz University of Medical Sciences, Shiraz, Iran, and also, Center for Development of Clinical Research of Nemazee Hospital and Dr Nasrin Shokrpour for editorial assistance.

\section{Disclosure}

The authors report no conflicts of interest in this work.

\section{References}

1. Nadeem M, Ather MH, Jamshaid A, Zaigham S, Mirza R, Salam B. Rationale use of unenhanced multi-detector CT (CT KUB) in evaluation of suspected renal colic. Int J Surg. 2012;10(10):634-637.

2. Smith-Bindman R, Aubin C, Bailitz J, et al. Ultrasonography versus computed tomography for suspected nephrolithiasis. $N$ Engl J Med. 2014;371(12):1100-1110.

3. Ulusan S, Koc Z, Tokmak N. Accuracy of sonography for detecting renal stone: comparison with CT. J Clin Ultrasound. 2007;35(5):256-261.

4. Ather MH, Jafri AH, Sulaiman MN. Diagnostic accuracy of ultrasonography compared to unenhanced $\mathrm{CT}$ for stone and obstruction in patients with renal failure. BMC Med Imaging. 2004;4(1):2.

5. Ulusan $\mathrm{S}, \mathrm{Koc} Z$, Tokmak N. Accuracy of sonography for detecting renal stone: comparison with CT. J Clin Ultrasound. 2007;35(5):256-261.

6. Pichler R, Skradski V, Aigner F, Leonhartsberger N, Steiner H. In young adults with a low body mass index ultrasonography is sufficient as a diagnostic tool for ureteric stones. BJU Int. 2012;109(5):770-774.

7. Kanno T, Kubota M, Sakamoto H, et al. The efficacy of ultrasonography for the detection of renal stone. Urology. 2014;84(2):285-288.

8. Patlas M, Farkas A, Fisher D, Zaghal I, Hadas-Halpern I. Ultrasound vs CT for the detection of ureteric stones in patients with renal colic. Br J Radiol. 2001;74(886):901-904. 
9. Fowler KA, Locken JA, Duchesne JH, Williamson MR. US for detecting renal calculi with nonenhanced CT as a reference standard. Radiology 2002;222(1):109-113.

10. Ray AA, Ghiculete D, Pace KT, Honey RJ. Limitations to ultrasound in the detection and measurement of urinary tract calculi. Urology. 2010;76(2):295-300.

11. King W, Kimme-Smith C, Winter J. Renal stone shadowing: an investigation of contributing factors. Radiology. 1985;154(1):191-196.
12. Rubens DJ, Bhatt S, Nedelka S, Cullinan J. Doppler artifacts and pitfalls. Radiol Clin North Am. 2006;44(6):805-835.

13. Goertz JK, Lotterman S. Can the degree of hydronephrosis on ultrasound predict kidney stone size? Am J Emerg Med. 2010;28(7):813-816.

14. Ray AA, Ghiculete D, Pace KT, Honey RJ. Limitations to ultrasound in the detection and measurement of urinary tract calculi. Urology. 2010;76(2):295-300.

\section{Publish your work in this journal}

Research and Reports in Urology is an international, peer-reviewed, open access journal publishing original research, reports, editorials, reviews and commentaries on all aspects of adult and pediatric urology in the clinic and laboratory including the following topics: Pathology, pathophysiology of urological disease; Investigation and treatment of urological disease; Pharmacology of drugs used for the treatment of urological disease. The manuscript management system is completely online and includes a very quick and fair peer-review system, which is all easy to use. Visit http://www.dovepress.com/testimonials.php to read real quotes from published authors. 